\title{
Novel artificial cell microencapsulation of a complex gliclazide-deoxycholic bile acid formulation: a characterization study
}

This article was published in the following Dove Press journal:

Drug Design, Development and Therapy

28 July 2014

Number of times this article has been viewed

\author{
Armin Mooranian' \\ Rebecca Negrulj' \\ Nigel Chen-Tan ${ }^{2}$ \\ Hesham S Al-Sallami ${ }^{3}$ \\ Zhongxiang Fang ${ }^{4}$ \\ Trilochan Mukkur \\ Momir Mikov ${ }^{6,7}$ \\ Svetlana Golocorbin-Kon ${ }^{6,7}$ \\ Marc Fakhoury ${ }^{8}$ \\ Frank Arfuso ${ }^{5}$ \\ Hani Al-Salami' \\ 'Biotechnology and Drug \\ Development Research Laboratory, \\ School of Pharmacy, Curtin Health \\ Innovation Research Institute, \\ Biosciences Research Precinct, \\ Curtin University, Perth, WA, \\ Australia; ${ }^{2}$ Faculty of Science and \\ Engineering, Curtin University, Perth, \\ WA, Australia; ${ }^{3}$ School of Pharmacy, \\ University of Otago, Dunedin, \\ New Zealand; ${ }^{4}$ School of Public \\ Health, Curtin University, Perth,WA, \\ Australia; ${ }^{5}$ Curtin Health Innovation \\ Research Institute, Biosciences \\ Research Precinct, School of \\ Biomedical Science, Curtin University, \\ Perth, WA, Australia; ${ }^{6}$ Department of \\ Pharmacology, Toxicology and Clinical \\ Pharmacology, Faculty of Medicine, \\ University of Novi Sad, Novi Sad, \\ Serbia; ${ }^{7}$ Department of Pharmacy, \\ Faculty of Medicine, University of \\ Montenegro, Podgorica, Montenegro; \\ ${ }^{8}$ Faculty of Medicine, Université de \\ Montréal, Montréal, Québec, Canada
}

Correspondence: Hani Al-Salami

School of Pharmacy, Curtin University,

GPO Box U1 987 Perth, WA 6845,

Australia

Tel +61892669816

Fax +6I 892662769

Email hani.al-salami@curtin.edu.au
Abstract: Gliclazide (G) is an antidiabetic drug commonly used in type 2 diabetes. It has extrapancreatic hypoglycemic effects, which makes it a good candidate in type 1 diabetes (T1D). In previous studies, we have shown that a gliclazide-bile acid mixture exerted a hypoglycemic effect in a rat model of T1D. We have also shown that a gliclazide-deoxycholic acid (G-DCA) mixture resulted in better $\mathrm{G}$ permeation in vivo, but did not produce a hypoglycemic effect. In this study, we aimed to develop a novel microencapsulated formulation of G-DCA with uniform structure, which has the potential to enhance $G$ pharmacokinetic and pharmacodynamic effects in our rat model of T1D. We also aimed to examine the effect that DCA will have when formulated with our new G microcapsules, in terms of morphology, structure, and excipients' compatibility. Microencapsulation was carried out using the Büchi-based microencapsulating system developed in our laboratory. Using sodium alginate (SA) polymer, both formulations were prepared: G-SA (control) at a ratio of 1:30, and G-DCA-SA (test) at a ratio of 1:3:30. Complete characterization of microcapsules was carried out. The new G-DCA-SA formulation was further optimized by the addition of DCA, exhibiting pseudoplastic-thixotropic rheological characteristics. The size of microcapsules remained similar after DCA addition, and these microcapsules showed no chemical interactions between the excipients. This was supported further by the spectral and microscopy studies, suggesting microcapsule stability. The new microencapsulated formulation has good structural properties and may be useful for the oral delivery of G in T1D.

Keywords: type 2 diabetes, bile acids, gliclazide, polymer

\section{Introduction}

Diabetes mellitus is a metabolic disorder classified as type 1 diabetes (T1D) or type 2 diabetes (T2D). T1D is an early-onset autoimmune disease marked by the destruction of $\beta$-cells of the pancreas, resulting in a partial or complete lack of insulin production and the inability of the body to control glucose homeostasis. ${ }^{1} \mathrm{~T} 2 \mathrm{D}$ is a metabolic disorder with later onset and is most common in the overweight population. ${ }^{2} \mathrm{~T} 2 \mathrm{D}$ is caused by genetic and environmental factors, with recent studies showing that loss of function gene variants in GPR120 have a strong association with increased risk of T2D complications. ${ }^{3,4}$ Gliclazide $(\mathrm{G})$ is an antidiabetic drug used in T2D to enhance insulin secretion, and has beneficial extrapancreatic effects that render it potentially useful in T1D. ${ }^{5}$ In general, controlled absorption of $\mathrm{G}$ from the gut is required in order to prevent sharp fluctuations in the blood glucose levels after food intake. About $30 \%$ of a $\mathrm{G}$ dose undergoes enterohepatic recirculation, which may contribute to the observed high bioavailability, but also high interindividual variability in its absorption after an 
oral dose. ${ }^{6}$ Thus, bile acids (BAs) may play an important role in enhancing $\mathrm{G}$ ileal absorption and optimize its efficacy and safety profiles.

BAs are known to act as permeation enhancers for antidiabetic drugs through the ileal mucosa and through the blood-brain barrier. ${ }^{7,8}$ BAs have also shown potential health benefits in diabetes treatment through their endocrinological, metabolic, energy expenditure, and other known and unknown effects. ${ }^{9,10}$ Combining BAs with $\mathrm{G}$ is anticipated to optimize G's antidiabetic effect. Our studies have shown the significant antidiabetic effects of the combination in a rat model of T1D. ${ }^{8,11}$ One of the potential applications of BAs on $\mathrm{G}$ is through enhancing its permeation. A recent study in our laboratory has demonstrated that the BA, deoxycholic acid (DCA), enhanced G permeation through the blood-brain barrier in T1D rats. ${ }^{8}$ In order to design this microencapsulated formulation of gliclazide-deoxycholic acid-sodium alginate (G-DCA-SA), a suitable polymer is needed.

Commonly used polymers in drug microencapsulation technology include sodium alignate (SA), chitosan, and pectin. ${ }^{12}$ They are biocompatible and present no signs of clinical toxicity. ${ }^{12} \mathrm{SA}$ is the salt of alginic acid, a natural polysaccharide derived from seaweed, and consisting of variable percentages of ( $1-4)$-linked $\beta$-d-mannuronic acid and $\alpha$-l-guluronic acid residues. ${ }^{13}$ In order to design a novel microencapsulated formulation that targets the lower intestine, low-viscosity SA (LVSA) is a good choice. ${ }^{14,15}$

This study aimed to design a novel G-DCA-SA microencapsulated formulation, using LVSA, that is uniform, biocompatible, and thermally stable and which has the potential for optimized G delivery.

\section{Materials and methods Materials}

G (99.92\%), LVSA (99\%), and DCA (99\%) were purchased from Sigma-Aldrich Co (St Louis, MO, USA). Calcium chloride dihydrate $\left(\left[\mathrm{CaCl}_{2} \cdot 2 \mathrm{H}_{2} \mathrm{O}\right] 98 \%\right)$ was obtained from Scharlab SL (Barcelona, Spain). All solvents and reagents were supplied by Merck (Darmstadt, Germany), and were of high-performance liquid chromatography (HPLC) grade and used without further purification.

\section{Drug preparation}

Stock suspensions of $\mathrm{G}(20 \mathrm{mg} / \mathrm{mL})$ and DCA $(1 \mathrm{mg} / \mathrm{mL})$ were prepared by adding the powder to $10 \%$ Ultra-soluble gel of $100 \mathrm{~mL}$ HPLC water. The $\mathrm{CaCl}_{2}$ stock solution (2\%) was prepared by adding $\mathrm{CaCl}_{2}$ powder to $\mathrm{HPLC}$ water. All preparations were mixed thoroughly at room temperature for
4 hours, stored in the refrigerator, and used within 48 hours of preparation.

\section{Preparation of microcapsules}

Microcapsules of G-loaded LVSA were prepared using a Büchibased microencapsulating system that operates through jet-flow microencapsulation. Parameters were set in a frequency range of 1,000-1,500 Hz and a constant flow rate of $4 \mathrm{~mL} / \mathrm{min}$. Polymer solutions containing SA and $\mathrm{G}$ with or without DCA were made up to a final concentration (of G-DCA-SA) in a ratio of 1:3:30, respectively. ${ }^{16,17}$ This ratio was based on our previously published work and was found to exhibit maximum consistency and best morphology. ${ }^{18}$ Two formulations were prepared, one with $\mathrm{G}(1 \mathrm{mg} / \mathrm{mL})$ in SA solution $(30 \mathrm{mg} / \mathrm{mL})$ and the other with $\mathrm{G}(1 \mathrm{mg} / \mathrm{mL})$, and DCA (3 mg/mL). Microcapsules were collected from our microencapsulating system and, for each formulation, three independent batches were prepared and tested separately $(n=3)$. All microcapsules (G-loaded and G-DCA-SA-loaded microcapsules) were prepared and treated in the exact same way. Microencapsulation efficiency was calculated as a percentage based on the total amount of $\mathrm{G}$ recovered, divided by total $\mathrm{G}$ used.

\section{Characterization of loaded microcapsules} Morphology, size analysis, and chemical characterization of microcapsules

All microcapsules were freshly made, stored in the refrigerator, and used within 48 hours of preparation. The appearance and size of microcapsules were examined using light microscopy followed by scanning electron microscopy (SEM) and energy dispersive X-ray (EDXR) spectrometry. The particle size distribution and mean particle size diameter were calculated using SmartSEM V05.03NV software (Carl Zeiss AG, Jena, Germany).

\section{SEM and EDXR spectroscopy}

The surface morphology of the microcapsules was examined using SEM (Zeiss Neon 40EsB FIBSEM; Carl Zeiss AG) with $0.8 \mathrm{~nm}$ calibrated resolution. The chemical characterization of the microcapsules was examined using EDXR (AztecEnergy EDS Analysis Software, Oxford Instruments, Oxfordshire, UK). Electron micrographs of G and G-DCA-SA microcapsules were obtained using SEM, and their chemical characterization was obtained using EDXR. The samples were mounted on a glass stub with double-sided adhesive tape and coated under vacuum with platinum $(5 \mathrm{~nm})$ in an argon atmosphere prior to examination. Micrographs with different magnifications were recorded to study the morphological 
and surface characteristics of the microcapsules. Multiple images at various scales and angles were taken, and those that best captured the details of the surface morphological changes were used.

\section{Determination of dispersing media viscosity}

Fifteen milliliter aliquots $(n=3)$ of both preparations (G-SA and G-DCA-SA) were taken from freshly prepared solutions, and the viscosity was measured at room temperature using a Visco 88 viscometer (Malvern Instruments Limited, Malvern, UK). The temperature remained constant at $23^{\circ} \mathrm{C}$ throughout the experiment (monitored by the Visco 88).

\section{Differential scanning calorimetry (DSC) analysis}

DSC thermograms of G, DCA, and LVSA powders, their physical mixture, and their microencapsulated formulations were carried out on a DSC instrument (DSC 8000; PerkinElmer Inc., Waltham, MA, USA). Five milligram samples were placed in sealed aluminum pans and heated at $20^{\circ} \mathrm{C} /$ min under a nitrogen atmosphere (flow rate $30 \mathrm{~mL} / \mathrm{min}$ ) in the $35^{\circ} \mathrm{C}-240^{\circ} \mathrm{C}$ range. An empty aluminum pan was used as a reference. The equipment was calibrated for baseline and temperature with zinc metal.

\section{Fourier transform infrared spectroscopy (FTIR) studies}

FTIR spectra of the pure components, their physical mixture, and the microcapsules were recorded via an attenuated total reflectance FTIR spectrometer (Spectrum Two ${ }^{\mathrm{TM}}$; PerkinElmer), and infrared measurements were performed in transmission in the scanning range of $450-4,000 \mathrm{~cm}^{-1}$ at room temperature. The same $\mathrm{G}$ to $\mathrm{SA}$ and $\mathrm{G}$ to DCA to SA ratios as those analytically determined in the microcapsules were used for preparing the different physical mixtures that served as controls.

\section{Results and discussion Morphology, size analysis, and chemical characterization of microcapsules}

Microcapsules were obtained using LVSA polymer, G, and DCA at a constant ratio of 30:1:3, respectively. Using our microencapsulation system, we were able to form microcapsules of a similar size. The mean diameters ranged from 1,000 to $1,150 \mu \mathrm{m}$ for all batches of both formulations. The mean particle size was not significantly affected by the presence of DCA (Figure 1). Microencapsulation efficiency remained similar, at $93 \% \pm 5 \%$ for G-SA and $90 \% \pm 7 \%$ for G-DCA-SA.

\section{SEM}

SEM studies of a G-SA microcapsule (Figure 2) and G-DCA-SA microcapsules (Figure 3) represent randomly selected microcapsules from a few freshly made batches. SEM results show microcapsules of consistent uniformity and well-defined spherical shapes. G-SA microcapsules (Figure 2) appeared slightly larger in size than the G-DCA-SA microcapsules (Figure 3). The microcapsule size difference between different formulations was not statistically significant. Due to the high-resolution images, we were able to conclude that the surfaces of the microcapsules were rough but consistent from one microcapsule to another in the sample used for all analyzed batches (Figures 2B-D and 3B-D).
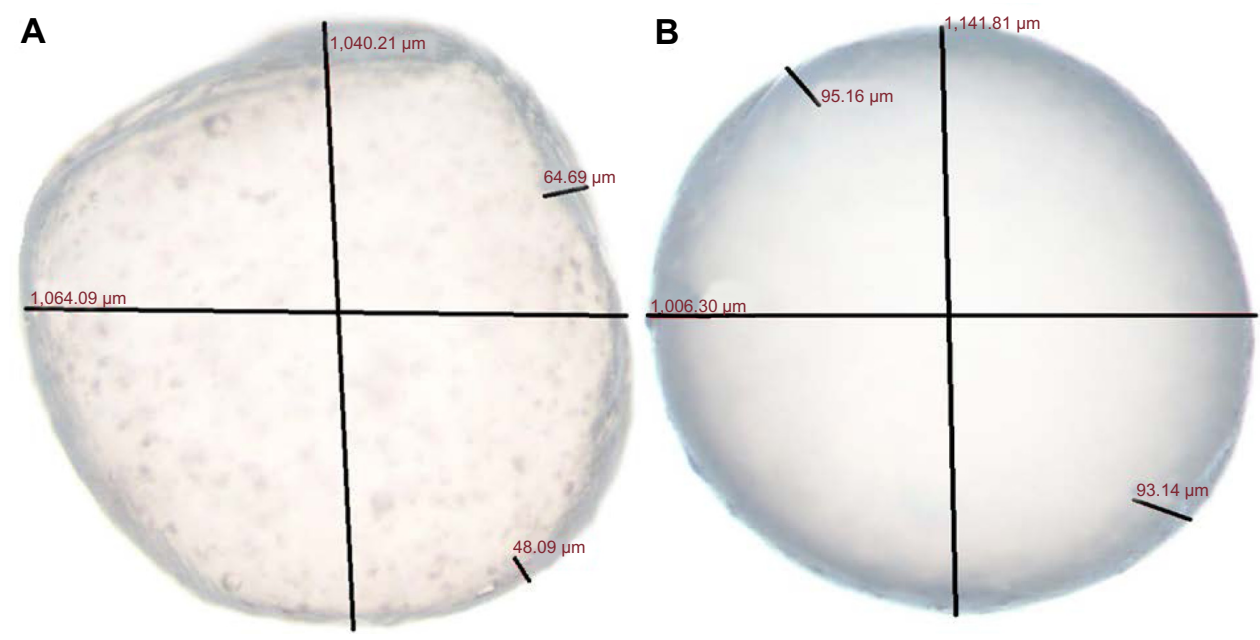

Figure I G-SA microcapsules (A) and G-DCA-SA microcapsules (B)

Abbreviations: G-DCA-SA, gliclazide-deoxycholic acid-sodium alginate; G-SA, gliclazide-sodium alginate. 


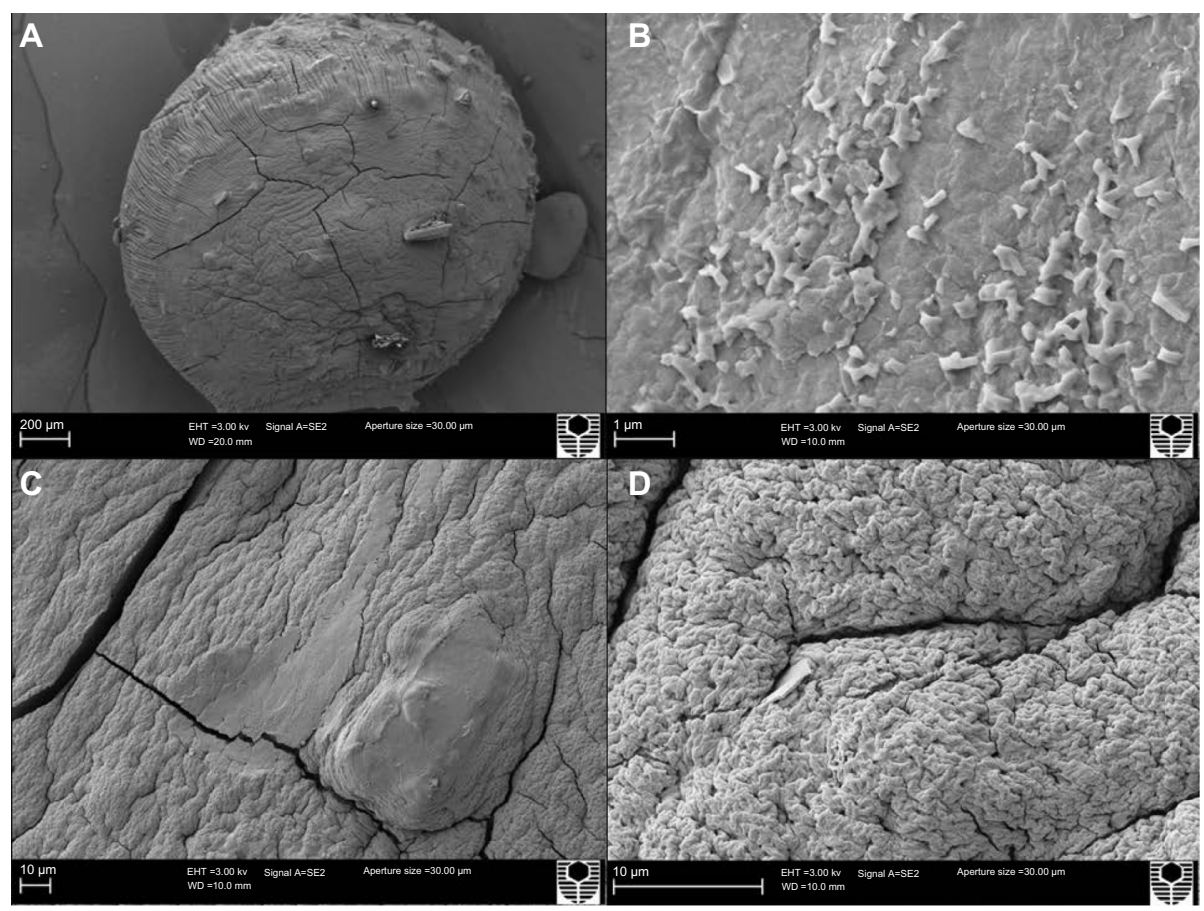

Figure 2 Scanning electron micrographs of gliclazide-sodium alginate microcapsules.

Notes: $200 \mu \mathrm{m}$ scale (A). Surface morphology at I $\mu \mathrm{m}$ scale (B) and I0 $\mu \mathrm{m}$ scale (C and D).

These high-resolution images also revealed ridges on the surface of the microcapsules with small crystal depositions. The small crystals distributed throughout the microcapsule surfaces were believed to be sodium chloride $(\mathrm{NaCl})$, which was confirmed by EDXR spectroscopy studies, as discussed below (Figures 4 and 5).

\section{EDXR spectroscopy}

In order to further analyze the composition of the microcapsule surface for the G-DCA-SA formulation, EDXR was used to identify the various surface crystal depositions and microcapsule composition including, various ions present on the surface of the microcapsules. Analysis of

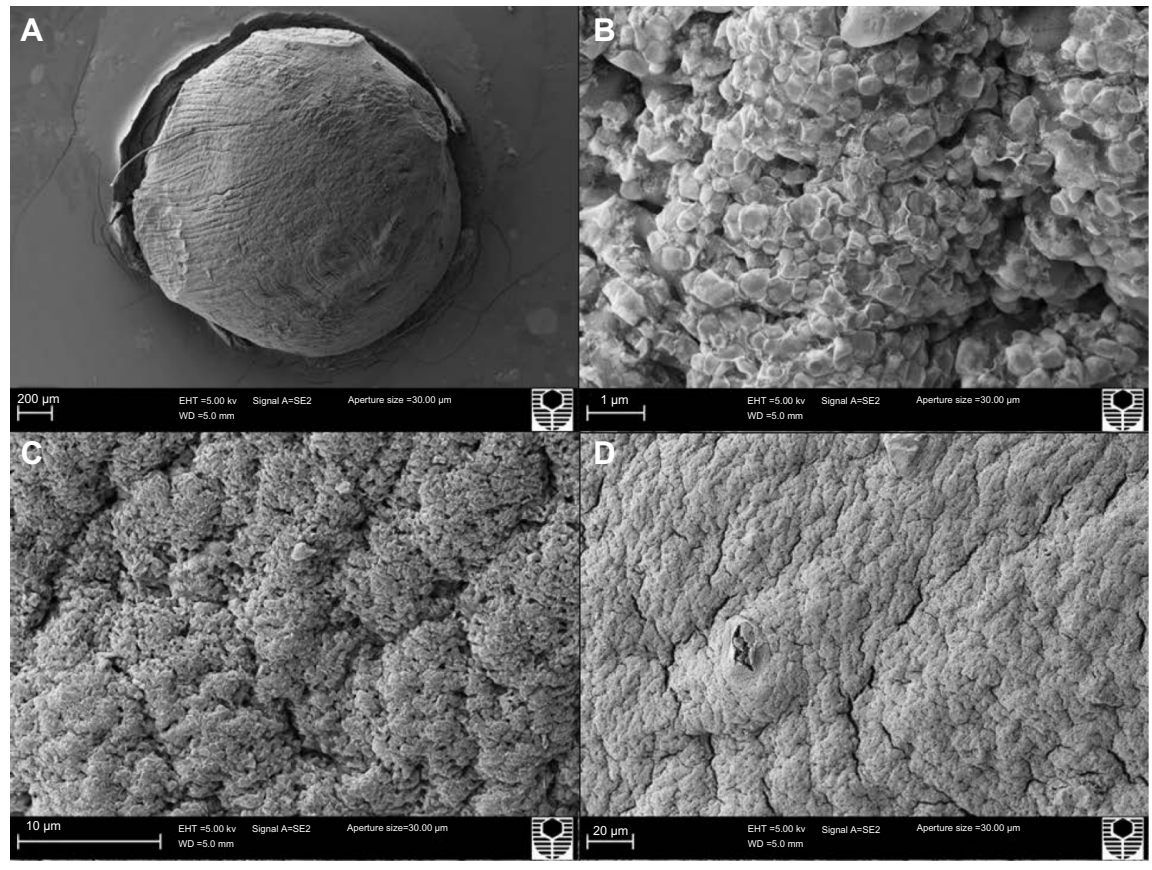

Figure 3 Scanning electron micrographs of gliclazide-deoxycholic acid-sodium alginate microcapsules at various angles.

Notes: $200 \mu \mathrm{m}$ scale (A). Surface morphology at I $\mu \mathrm{m}$ scale (B), $10 \mu \mathrm{m}$ scale (C), and $20 \mu \mathrm{m}$ scale (D). 


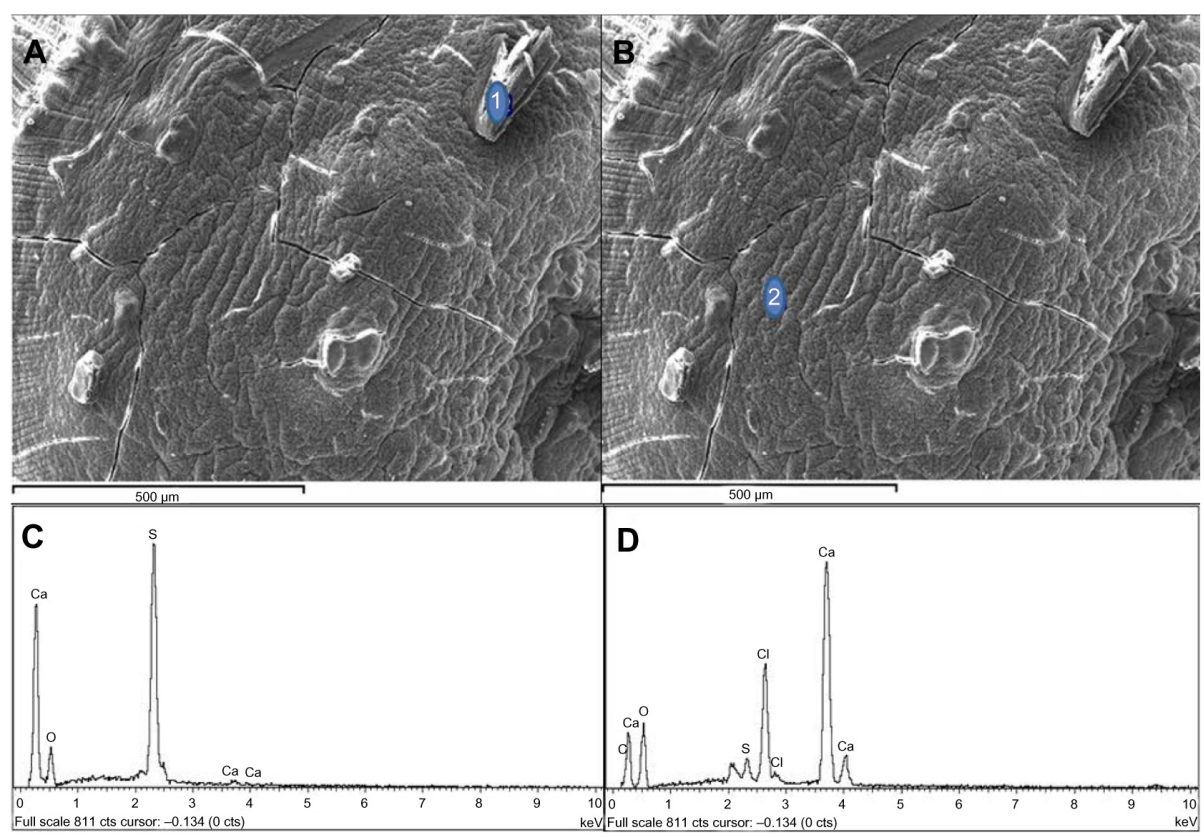

Figure 4 Energy-dispersive $X$-ray spectra of the gliclazide-sodium alginate microcapsules.

Notes: Drug composition (A) and surface composition (B), with corresponding analysis (C and $\mathbf{D})$. I in (A), and 2 in (B) represent the sites where EDXR spectroscopy analyses were undertaken.

Abbreviation: EDXR, energy dispersive X-ray.

crystal depositions on the microcapsule surfaces (Figure 5) revealed high levels of $\mathrm{Na}$ and $\mathrm{Cl}$ ions, confirming that there were small crystals of $\mathrm{NaCl}$ on the surface of G-DCA-SA microcapsules; this was expected, given sodium chloride is a by-product of the ionic-gelation methodology of microcapsule production. ${ }^{16,19,20}$ Both formulations showed high levels of sulfur, oxygen, and carbon, confirming the presence of $\mathrm{G}$ within the polymer matrix for the formulation, although carbon and oxygen are also common to DCA and SA. As for the microcapsule surface composition, EDXR revealed high levels of calcium, carbon, and oxygen, which were expected, given the microcapsule wall structure and DCA-reinforced calcium alginate matrix system.

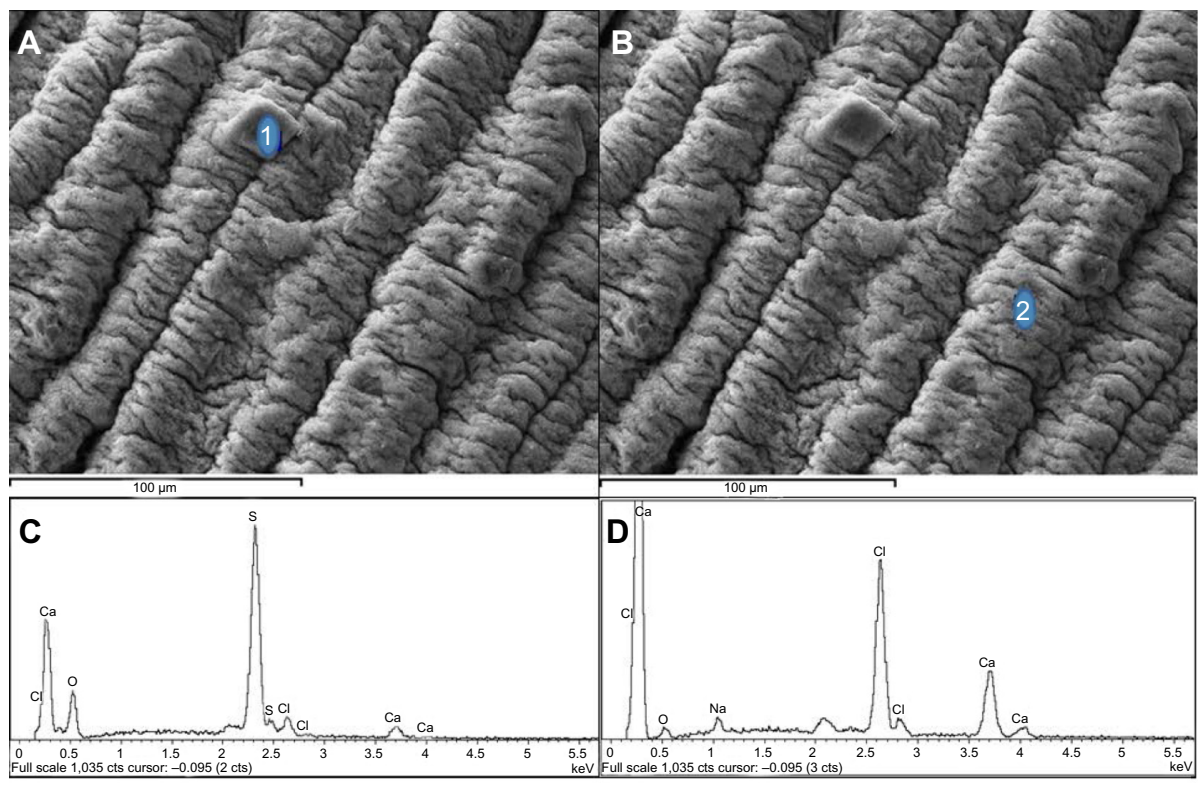

Figure 5 Energy-dispersive $X$-ray spectra of the gliclazide-deoxycholic acid-sodium alginate microcapsules.

Notes: Drug composition (A) and surface composition (B), with corresponding analysis (C and $\mathbf{D})$. I in (A), and 2 in (B) represent the sites where EDXR spectroscopy analyses were undertaken

Abbreviation: EDXR, energy dispersive X-ray 
The EDXR assessment of G-SA microcapsules is shown in Figure 4, which reveals the surface where analyses were done. Figure 4A shows the core of the G-SA microcapsule with the corresponding EDXR spectrum (Figure 4C). The spectrum shows a high concentration of the sulfur (S) atom, unique to the drug $\mathrm{G}$, as no other excipient in the formulation contained $\mathrm{S}$ atoms. The spectrum also reveals high concentrations of calcium $(\mathrm{Ca})$ and oxygen $(\mathrm{O})$, which are likely to correspond to the surrounding calcium alginate membrane. Figure 4B, on the other hand, is an analysis of the surface, with the corresponding EDXR spectrum shown in Figure 4D. Figure 4D shows predominant $\mathrm{Ca}$ and $\mathrm{O}$ activity corresponding to the general surface composition, with some $\mathrm{S}$ detected, likely due to the deposition of small drug crystals nearby or to the penetration of electron rays in the membrane deep enough to detect the encapsulated drug.

An example of an EDXR assessment of G-DCA-SA microcapsules is shown in Figure 5A, with the respective spectrum of the microcapsule surface. In Figure $5 \mathrm{C}$, the microcapsule surfaces were not perfectly homogenous, thus varying crystal depositions could occur at selected sites across the microcapsule surface. Figure 5A exemplifies the core of the G-DCA-SA microcapsules, and Figure 5C shows a high concentration of $\mathrm{S}$ atoms, which is expected from $\mathrm{G}$ molecules. Figure 5B illustrates the surface surrounding the drug in the G-DCA-SA microcapsules, and Figure 5D shows a high concentration of $\mathrm{Cl}$ and $\mathrm{Ca}$ atoms, which are expected to adhere to the surface of the microcapsules. These atoms derive from the used vehicle carrying the formed microcapsules $\left(\mathrm{CaCl}_{2}\right)$. Furthermore, Figure 5C and D show the chemical characteristics of the microcapsules, with dominant ions $(\mathrm{Na}, \mathrm{O}, \mathrm{Ca}$, and $\mathrm{Cl})$ that are expected for typical G-DCA-SA microcapsules prepared via ionicgelation methodology.

\section{Viscosity of the microencapsulated formulation}

Table 1 shows the viscosity, shear rate, shear stress, and torque force for all microencapsulated formulations under various speeds $(20,35,61,107,187,327,572$, and 1,000 rpm). The G-SA formulation was more viscous, but both formulations behaved as almost non-Newtonian fluids under shear stress. Thus, and as anticipated from our previous studies, both formulations behave as thixotropic non-Newtonian fluids under increasing stress, as evidenced by parallel reductions in their apparent viscosity. ${ }^{16,17}$ Further evidence of the thixotropic-pseudoplastic behavior of both formulations can be seen in the proportional increases in torque and shear rate following rising shear stress forces and associated decrease in the viscosity, characteristic of non-Newtonian fluid, and thixotropic behavior of the polymer. ${ }^{21-27}$ The application of the stirring rod in the solutions at increasing speeds resulted in the solutions forming rapid circular motions away from the site of centripetal force origin, suggesting that both formulations also behaved in a non-Weissenberg fashion. ${ }^{27,28}$

\section{Thermal analysis of the microcapsules}

DSC is an important technology for the thermal characterization of various materials. DSC establishes a connection between temperature and specific physical properties of substances, such as crystallization and melting temperature. It is commonly used to determine the enthalpy

Table I Viscosities and related parameters of both microencapsulated formulations: G-SA and G-DCA-SA ( $n=3$ )

\begin{tabular}{|c|c|c|c|c|c|c|}
\hline Formula code & Setting & $\begin{array}{l}\text { Speed } \\
\text { (rpm) }\end{array}$ & $\begin{array}{l}\text { Viscosity } \\
\text { (mPa's) }\end{array}$ & $\begin{array}{l}\text { Shear rate } \\
\left(\mathrm{s}^{-1}\right)\end{array}$ & $\begin{array}{l}\text { Torque } \\
(\mathrm{mN} \cdot \mathrm{m})\end{array}$ & $\begin{array}{l}\text { Shear stress } \\
(\mathrm{Pa})\end{array}$ \\
\hline \multirow[t]{8}{*}{ G-SA } & 1 & 20 & UD & UD & UD & UD \\
\hline & 2 & 35 & UD & UD & UD & UD \\
\hline & 3 & 61 & UD & UD & UD & UD \\
\hline & 4 & 107 & $37 \pm 0.35$ & $124.9 \pm 0 . \mid$ & $0.17 \pm 0.01$ & $4.6 \pm 0.04$ \\
\hline & 5 & 187 & $34 \pm 0.34$ & $221.8 \pm 0.25$ & $0.28 \pm 0.03$ & $7.7 \pm 0.01$ \\
\hline & 6 & 327 & $30 \pm 0.3$ & $385.1 \pm 0.4$ & $0.43 \pm 0.05$ & $11.6 \pm 0.04$ \\
\hline & 7 & 572 & $26 \pm 0.26$ & $680.5 \pm 0.7$ & $0.64 \pm 0.04$ & $17.3 \pm 0.02$ \\
\hline & 8 & 1,000 & $21 \pm 0.2$ & $1,194 \pm 1$ & $0.93 \pm 0.06$ & $25.4 \pm 0.06$ \\
\hline \multirow[t]{8}{*}{ G-DCA-SA } & I & 20 & UD & UD & UD & UD \\
\hline & 2 & 35 & UD & UD & UD & UD \\
\hline & 3 & 61 & UD & UD & UD & UD \\
\hline & 4 & 107 & UD & UD & UD & UD \\
\hline & 5 & 187 & $24 \pm 0.24$ & $221.9 \pm 0.3$ & $0.19 \pm 0.02$ & $5.1 \pm 0.05$ \\
\hline & 6 & 327 & $23 \pm 0.22$ & $385.3 \pm 0.5$ & $0.34 \pm 0.04$ & $9.1 \pm 0.03$ \\
\hline & 7 & 572 & $21 \pm 0.21$ & $680.8 \pm 0.7$ & $0.60 \pm 0.04$ & $16.2 \pm 0.06$ \\
\hline & 8 & 1,000 & $20 \pm 0.2$ & $1,195 \pm 2$ & $0.97 \pm 0.1$ & $26.4 \pm 0.03$ \\
\hline
\end{tabular}

Abbreviations: G-DCA-SA, gliclazide-deoxycholic acid-sodium alginate; G-SA, gliclazide-sodium alginate; UD, undetected (below the instrument limit of detection). 
associated with the process of microencapsulation. ${ }^{29}$ In microencapsulation, DSC measures how physical properties of $\mathrm{G}$ and DCA molecules change, along with temperature against time..$^{30,31}$ This occurs through determining the temperature and heat flow $\left(35^{\circ} \mathrm{C}-240^{\circ} \mathrm{C}\right)$ associated with $\mathrm{G}$ transitions as a function of time. DSC spectra were analyzed for G powder (Figure 6A), DCA powder (Figure 6B), SA powder (Figure 6C), G-DCA-SA powder (Figure 6D), G-SA microcapsules (Figure 6E), and G-DCA-SA microcapsules (Figure 6F).

DSC analysis of DCA powder (Figure 6B) showed a small peak at $178^{\circ} \mathrm{C}$, indicative of a DCA melting point. A similar peak at $179^{\circ} \mathrm{C}$ was clearly observed with $\mathrm{G}$ analysis (Figure 6A), which is indicative of its melting point. The DSC analysis of DCA and G microcapsules (Figure 6F) showed transparent and interference-free integration of two predominant peaks - one corresponding to $\mathrm{G}$, and the other a slight shift to the right when compared to individual DCA and SA powders, which could represent possible chemical interactions between SA and DCA in the microcapsule
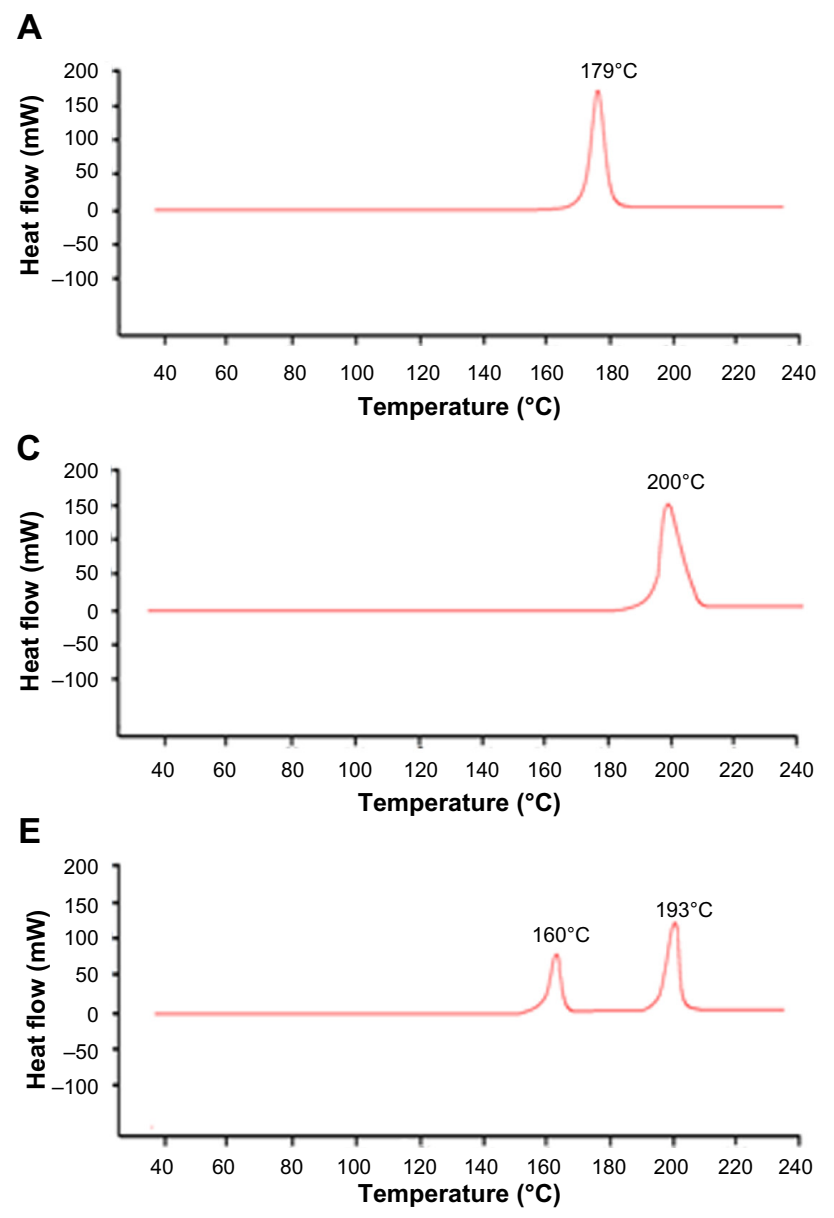

matrix, alterations in the crystallinity of DCA and SA within the temperature range used for analysis, or polymorphism leading to an endothermic shift to the right. ${ }^{32,33}$

As for the G-SA microcapsule (Figure 6E) analysis, there was a very similar graph with two prominent peaks one representing $\mathrm{G}\left(160^{\circ} \mathrm{C}\right)$, and the other the SA powder $\left(193^{\circ} \mathrm{C}\right)$, and could represent plasticization of the polymer..$^{34}$ SA powder (Figure 6C) showed a significant peak at $200^{\circ} \mathrm{C}$, indicative of the endothermic thermal behavior of the polymer and in line with the SA peak observed at $200^{\circ} \mathrm{C}$ in G-DCA-SA microcapsules (Figure 6F). ${ }^{35} \mathrm{G}$ was not chemically modified or did not participate in any significant reaction, as evidenced by endothermic peaks characteristic of the drug following analysis of the microcapsules. ${ }^{36,37}$ This was confirmed by the combined powders of G, DCA, and SA (Figure 6D), which showed two peaks representing the $\mathrm{G}$ and SA peaks, which was a slight shift from the original $G$ peak, thus suggesting that there were no significant chemical interactions occurring between DCA, G, and SA in the powder form. However, there remains the possibility of G and DCA
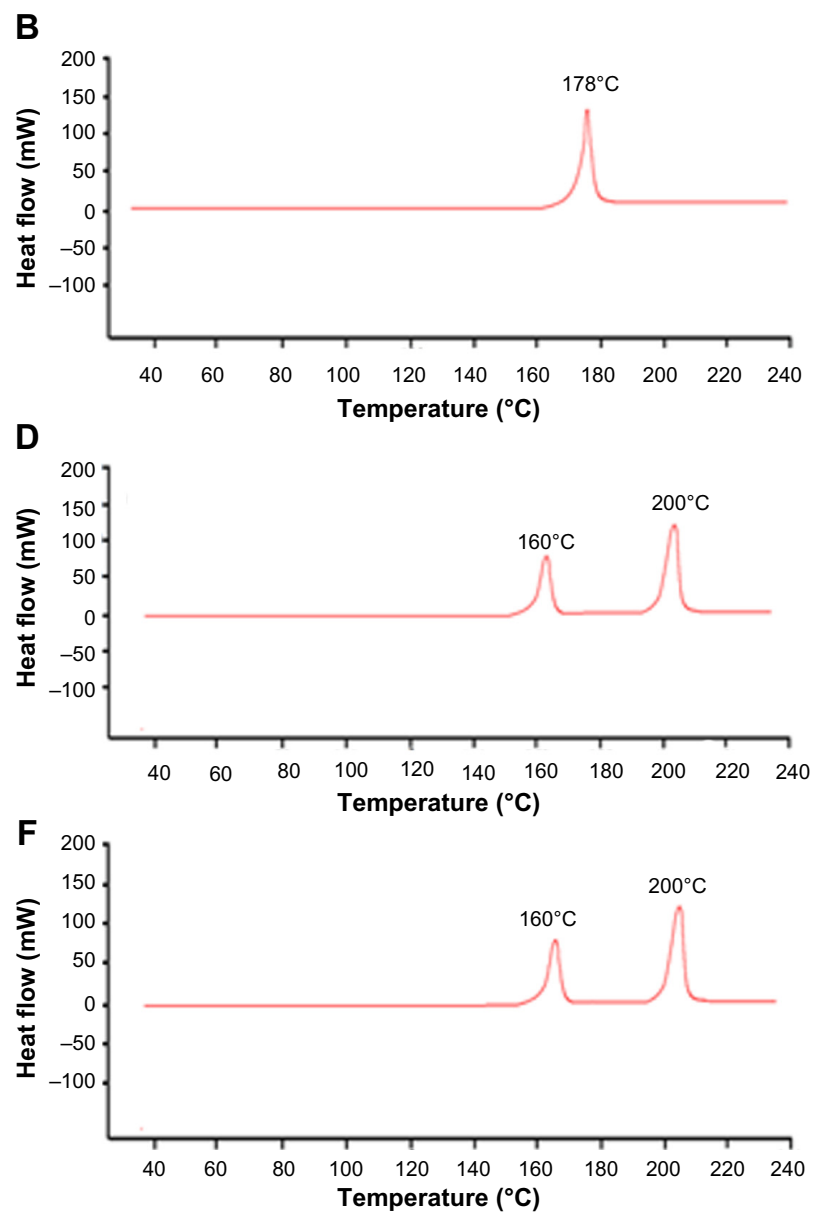

Figure 6 Differential scanning calorimetry thermograms of G powder (A), DCA powder (B), SA powder (C), G-DCA-SA powder (D), G-SA microcapsules (E), and G-DCASA microcapsules (F).

Abbreviations: DCA, deoxycholic acid; G-DCA-SA, gliclazide-deoxycholic acid-sodium alginate; G-SA, gliclazide-sodium alginate; SA, sodium alginate; G, gliclazide. 
peaks overlapping. Overall, this indicates good stability of $\mathrm{G}$ and DCA in the formulated microcapsules. Interestingly, the DCA peak (Figure 6B) noted in the DCA individual powder did not appear in the G-DCA-SA powder mixture of the combined powders (Figure 6D). This may be due to a shift in the thermal capacity within the $35^{\circ} \mathrm{C}-240^{\circ} \mathrm{C}$ range, or to interactions or potential crystallinity. ${ }^{30,37}$ The DCA peak was also absent in the G-DCA-SA microcapsules, possibly due to DCA formulated in the combined G-DCA-SA microcapsules existing in an amorphous or disordered crystalline phase as well as a solid state solution (Figure 6F). ${ }^{37}$

The shift in the thermal profile of $\mathrm{G}$ in the microencapsulation form (Figure 6E) suggests that the drug solubilizes in the polymer matrix via ionic interactions, while no significant chemical reaction takes place between $\mathrm{G}$ or any of the formulation excipients, as shown by FTIR studies (Figure 7) and previous in vivo and ex vivo work in our laboratory. ${ }^{14,34,38-40}$ Comparing all peaks, G does not apparently participate in significant crosslinking reactions, and retains its chemical integrity during the microencapsulation process, as evidenced by FTIR studies.

\section{FTIR spectral studies}

The FTIR spectra were used to confirm the chemical compatibility of G with the SA polymer and DCA in the microencapsulation formulation. FTIR spectra were analyzed for $\mathrm{G}$ powder (Figure 7A), DCA powder (Figure 7B), SA powder (Figure 7C), G-DCA-SA powder (Figure 7D), G-SA
A
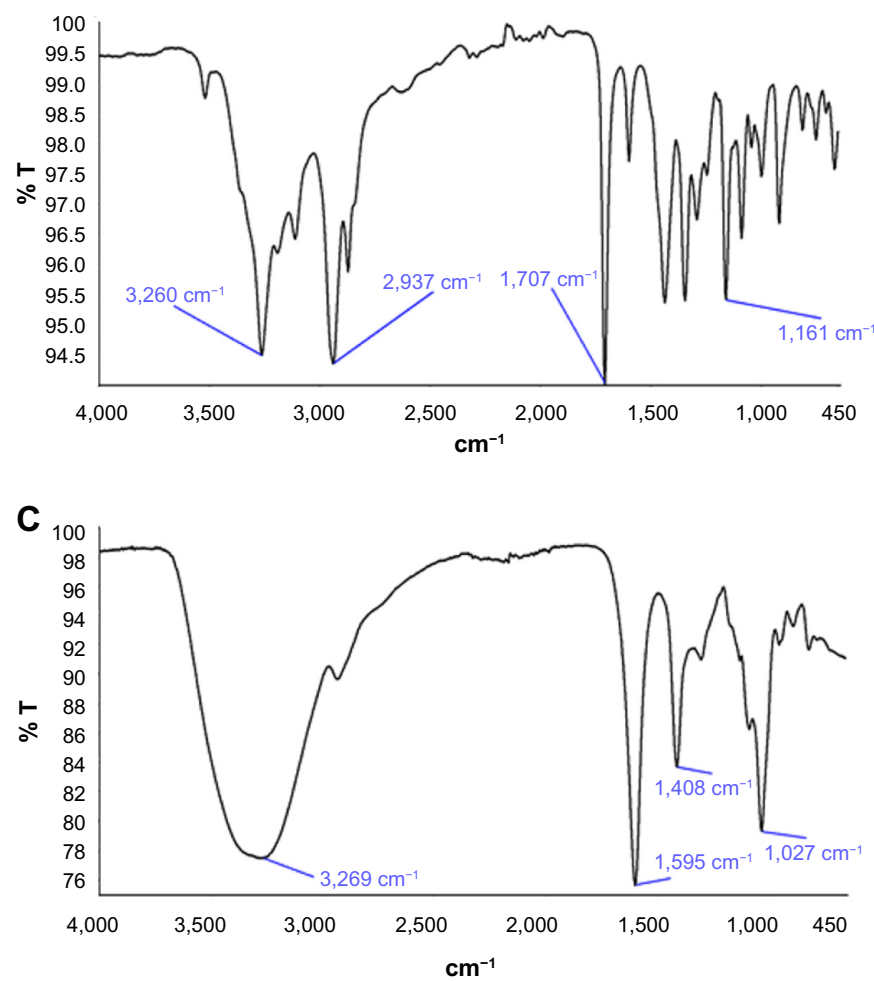

E

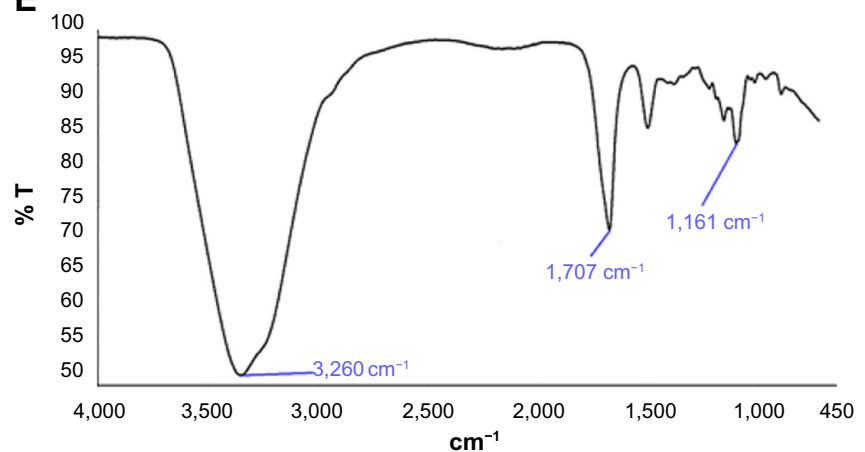

B

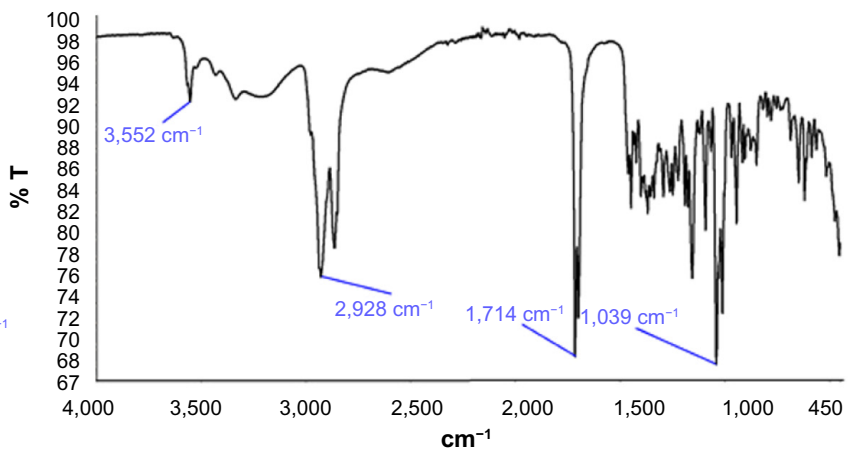

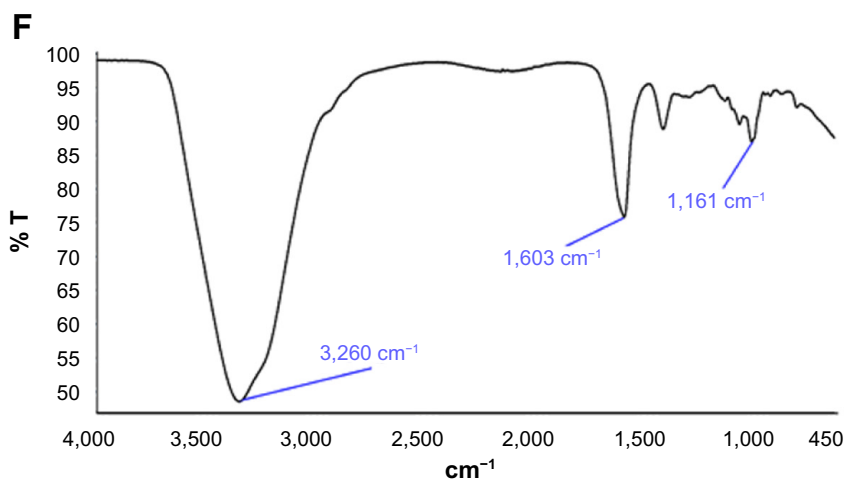

Figure 7 Fourier transform infrared spectra of G powder (A), DCA powder (B), SA powder (C), G-DCA-SA powder (D), G-SA microcapsules (E), and G-DCA-SA microcapsules (F).

Abbreviations: DCA, deoxycholic acid; G-DCA-SA, gliclazide-deoxycholic acid-sodium alginate; G-SA, gliclazide-sodium alginate; SA, sodium alginate; G, gliclazide; T, transmittance. 
microcapsules (Figure 7E), and G-DCA-SA microcapsules (Figure 7F).

The spectrum of G-SA for the $\mathrm{C}=\mathrm{O}$ band in carbonyl group shows a sharp peak at $1,707 \mathrm{~cm}^{-1}$ (Figure 7A), which was consistent across both microencapsulated formulations (Figure 7E and F) and powder mixture (Figure 7D). Again, for the $\mathrm{S}=\mathrm{O}$ band in sulfonamide, the G-SA spectra show peaks at $1,161 \mathrm{~cm}^{-1}$, and for the amino group, peaks of $3,260 \mathrm{~cm}^{-1}$ in the microcapsules and powder mixture. For DCA powder (Figure 7B), the spectrum is in line with previously published work. ${ }^{41}$ In G-DCA-SA microcapsules (Figure 7F) and G-DCA-SA powder (Figure 7D), there was a small shift of the $G$ peak to the right $\left(1,603 \mathrm{~cm}^{-1}\right)$. This may be due to the dilution of DCA concentration in the mixture, or may occur during the microencapsulation process. The more likely reason is the dilution of the powder in the G-DCA-SA mixture, which is in line with the thermal analysis above (Figure 6D). In addition, the FTIR spectrum of SA powder (Figure 7C) is consistent with the literature; ${ }^{42}$ however, the spectra of G-DCA-SA microcapsules and G-DCA-SA powder mixture seem to be weaker and seem to display less bond-peak activity. ${ }^{43}$ This may be due to the dilution of the sample, which is consistent with the thermal analysis of the G-DCA-SA powder mixture (Figure 7D). Overall, FTIR spectra of G suggest that microencapsulation of G with SA and DCA does not significantly compromise the chemical composition and structural integrity of the $\mathrm{G}$ molecules, as no significant chemical reaction occurred between the drug and any of the formulation excipients.

\section{Conclusion}

Microencapsulation of G and DCA is a novel and viable technique that is useful for targeted drug delivery. The new formulation designed in this study displays appropriate excipient compatibility and structural morphology with thixotropic-pseudoplastic behavior. This microencapsulated formulation is expected to ensure adequate encapsulation of labile compounds, such as primary BAs, which seem beneficial in conjunction with $\mathrm{G}$, in diabetes treatment. Along with the use of microencapsulation, DCA will play a crucial role in optimizing $\mathrm{G}$ absorption in the ileum, which will help to further increase its antidiabetic effect. However, more work is needed to better evaluate the drug release profile from the microcapsules. The authors' future study aims at investigating the release kinetics of the formulation in various $\mathrm{pH}$ and temperature values and establishing its targeted delivery characteristics, which is anticipated to have significant impact on future in vivo studies.

\section{Acknowledgments}

The authors acknowledge the CHIRI at Curtin University, the Curtin-seeding grant for support, and the use of equipment and scientific and technical assistance of the Curtin University Electron Microscope Facility, which has been partially funded by the university, and state and Commonwealth governments.

\section{Disclosure}

The authors report no conflicts of interest in this work.

\section{References}

1. Barbeau WE, Bassaganya-Riera J, Hontecillas R. Putting the pieces of the puzzle together - a series of hypotheses on the etiology and pathogenesis of type 1 diabetes. Med Hypotheses. 2007;68:607-619.

2. Ferrannini E. Insulin resistance versus insulin deficiency in non-insulindependent diabetes mellitus: problems and prospects. Endocr Rev. 1998;19:477-490.

3. Oh DY, Olefsky JM. Omega 3 fatty acids and GPR120. Cell Metab. 2012;15:564-565.

4. Burns RN, Moniri NH. Agonism with the omega-3 fatty acids alphalinolenic acid and docosahexaenoic acid mediates phosphorylation of both the short and long isoforms of the human GPR120 receptor. Biochem Biophys Res Commun. 2010;396:1030-1035.

5. Al-Salami H, Butt G, Tucker I, Skrbic R, Golocorbin-Kon S, Mikov M. Probiotic treatment proceeded by a single dose of bile acid and gliclazide exert the most hypoglycemic effect in Type 1 diabetic rats. Medical Hypothesis Research. 2008;4: 93-101.

6. Taylor AR, Brownsill RD, Grandon H, et al. Pharmacokinetics and pharmacodynamics of gliclazide in Caucasians and Australian Aborigines with type 2 diabetes. Br J Clin Pharmacol. 2000;49: 223-230.

7. Al-Salami H, Butt G, Tucker I, Mikov M. Influence of the semisynthetic bile acid MKC on the ileal permeation of gliclazide in vitro in healthy and diabetic rats treated with probiotics. Methods Find Exp Clin Pharmacol. 2008;30:107-113.

8. Lalić-Popović M, Vasović V, Milijašević B, Goločorbin-Kon S, Al-Salami H, Mikov M. Deoxycholic acid as a modifier of the permeation of gliclazide through the blood brain barrier of a rat. J Diabetes Res. 2013;2013:598603.

9. Houten SM, Watanabe M, Auwerx J. Endocrine functions of bile acids. EMBO J. 2006;25:1419-1425.

10. Negrulj R, Mooranian A, Al-Salami H. Potentials and limitations of bile acids in type 2 diabetes mellitus: applications of microencapsulation as a novel oral delivery system. Journal of Endocrinology and Diabetes Mellitus. 2013;1:49-59.

11. Mikov M, Al-Salami H, Golocorbin-Kon S, Skrbic R, Raskovic A, Fawcett JP. The influence of 3alpha, 7alpha-dihydroxy-12-keto-5betacholanate on gliclazide pharmacokinetics and glucose levels in a rat model of diabetes. Eur J Drug Metab Pharmacokinet. 2008;33: 137-142.

12. Efentakis M, Buckton G. The effect of erosion and swelling on the dissolution of theophylline from low and high viscosity sodium alginate matrices. Pharm Dev Technol. 2002;7:69-77.

13. Al-Kassas RS, Al-Gohary OM, Al-Faadhel MM. Controlling of systemic absorption of gliclazide through incorporation into alginate beads. Int J Pharm. 2007;341:230-237.

14. Takka S, Acartürk F. Calcium alginate microparticles for oral administration: I: Effect of sodium alginate type on drug release and drug entrapment efficiency. J Microencapsul. 1999;16:275-290.

15. Fakhoury M, Coussa-Charley M, Al-Salami H, Kahouli I, Prakash S. Use of artificial cell microcapsule containing thalidomide for treating TNBS-induced Crohn's disease in mice. Curr Drug Deliv. 2014;11:146-153. 
16. Al-Salami H, Butt G, Tucker I, et al. Gliclazide reduces MKC intestinal transport in healthy but not diabetic rats. Eur J Drug Metab Pharmacokinet. 2009;34:43-50.

17. Al-Salami H, Butt G, Tucker I, Mikov M. Influence of the semisynthetic bile acid (MKC) on the ileal permeation of gliclazide in healthy and diabetic rats. Methods Find Exp Clin Pharmacol. 2008;30:107-113.

18. Mooranian A, Negrulj R, Mathavan S, et al. A complex microencapsulated system: a platform for optimised oral delivery of antidiabetic drug-bile acid formulations. Pharm Dev Technol. In press 2014.

19. Mikov M, Al-Salami H, Kuhajda K, Kevresan S, Golocorbin-Kon S, Fawcett JP. Pharmacokinetics and hypoglycemic activity of the semisynthetic bile acid salt, sodium 3a,7o-dihydroxy-12-oxo-5j3-cholanate in diabetic rats. FEBS Congress, Istanbul, June 2006. The FEBS Journal. 2006;273 (Suppl 1):210.

20. Pal D, Nayak AK. Development, optimization, and anti-diabetic activity of gliclazide-loaded alginate-methyl cellulose mucoadhesive microcapsules. AAPS PharmSciTech. 2011;12:1431-1441.

21. Prajapati S, Tripathi P, Ubaidulla U, Anand V. Design and development of gliclazide mucoadhesive microcapsules: in vitro and in vivo evaluation. AAPS PharmSciTech. 2008;9:224-230.

22. Yang Y, Campanella OH, Hamaker BR, Zhang G, Gu Z. Rheological investigation of alginate chain interactions induced by concentrating calcium cations. Food Hydrocoll. 2013;30:26-32.

23. Barakat NS, Shazly GA, Almedany AH. Influence of polymer blends on the characterization of gliclazide - encapsulated into poly ( $\varepsilon$-caprolactone) microparticles. Drug Dev Ind Pharm. 2013;39: 352-362.

24. de Celis Alonso B, Rayment P, Ciampi E, et al. NMR relaxometry and rheology of ionic and acid alginate gels. Carbohydr Polym. 2010;82:663-669.

25. Draget KI, Taylor C. Chemical, physical and biological properties of alginates and their biomedical implications. Food Hydrocoll. 2011;25:251-256.

26. Bonino CA, Samorezov JE, Jeon O, Alsberg E, Khan SA. Real-time in situ rheology of alginate hydrogel photocrosslinking. Soft Matter. 2011;7:11510-11517.

27. Pamies R, Rodríguez Schmidt R, López Martínez MC, García de la Torre J. The influence of mono and divalent cations on dilute and non-dilute aqueous solutions of sodium alginates. Carbohydr Polym. 2010;80:248-253.

28. Legrand J, Dumont E, Comiti J, Fayolle F. Diffusion coefficients of ferricyanide ions in polymeric solutions - comparison of different experimental methods. Electrochim Acta. 2000;45:1791-1803.

29. Desai SR, Dharwadkar SR. Study of polymorphic transformation of ornidazole drug by differential scanning calorimetry and other complementary techniques. Acta Pol Pharm. 2008;65:409-413.
30. Gill P, Moghadam TT, Ranjbar B. Differential scanning calorimetry techniques: applications in biology and nanoscience. J Biomol Tech. 2010;21:167-193.

31. Al-Salami H, Butt G, Fawcett JP, Tucker IG, Golocorbin-Kon S, Mikov M. Probiotic treatment reduces blood glucose levels and increases systemic absorption of gliclazide in diabetic rats. Eur J Drug Metab Pharmacokinet. 2008;33:101-106.

32. Kulkarni AR, Soppimath KS, Aminabhavi TM, Rudzinski WE. In-vitro release kinetics of cefadroxil-loaded sodium alginate interpenetrating network beads. Eur J Pharm Biopharm. 2001;51:127-133.

33. Sarmento B, Ferreira D, Veiga F, Ribeiro A. Characterization of insulinloaded alginate nanoparticles produced by ionotropic pre-gelation through DSC and FTIR studies. Carbohydr Polym. 2006;66:1-7.

34. Takka S, Cali AG. Bile salt-reinforced alginate-chitosan beads. Pharm Dev Technol. 2012;17:23-29.

35. Barakat NS, Almurshedi AS. Design and development of gliclazide loaded chitosan microparticles for oral sustained drug delivery: in-vitro/in-vivo evaluation. J Pharm Pharmacol. 2011;63:169-178.

36. Thybo P, Pedersen BL, Hovgaard L, Holm R, Mullertz A. Characterization and physical stability of spray dried solid dispersions of probucol and PVP-K30. Pharm Dev Technol. 2008;13:375-386.

37. Ajun W, Yan S, Li G, Huili L. Preparation of aspirin and probucol in combination loaded chitosan nanoparticles and in vitro release study. Carbohydr Polym. 2009;75:566-574.

38. Bakatselou V, Oppenheim RC, Dressman JB. Solubilization and wetting effects of bile salts on the dissolution of steroids. Pharm Res. 1991;8:1461-1469.

39. Martoni C, Bhathena J, Urbanska AM, Prakash S. Microencapsulated bile salt hydrolase producing Lactobacillus reuteri for oral targeted delivery in the gastrointestinal tract. Appl Microbiol Biotechnol. 2008;81:225-233.

40. Al-Salami H, Butt G, Tucker I, Skrbic R, Golocorbin-Kon S, Mikov M. Probiotic pre-treatment reduces gliclazide permeation (ex vivo) in healthy rats but increases it in diabetic rats to the level seen in untreated healthy rats. Arch Drug Inf. 2008;1:35-41.

41. Yang L, Xu Y, Su Y, et al. FT-IR spectroscopic study on the variations of molecular structures of some carboxyl acids induced by free electron laser. Spectrochim Acta A Mol Biomol Spectrosc. 2005;62:1209-1215.

42. Daemi H, Barikani M. Synthesis and characterization of calcium alginate nanoparticles, sodium homopolymannuronate salt and its calcium nanoparticles. Scientia Iranica, 2012;19(6):2023-2028.

43. Devi MP, Sekar M, Chamundeswari M, et al. A novel wound dressing material - fibrin-chitosan-sodium alginate composite sheet. Bulletin of Materials Science. 2012;35:1157-1163.
Drug Design, Development and Therapy

\section{Publish your work in this journal}

Drug Design, Development and Therapy is an international, peerreviewed open-access journal that spans the spectrum of drug design and development through to clinical applications. Clinical outcomes, patient safety, and programs for the development and effective, safe, and sustained use of medicines are a feature of the journal, which

\section{Dovepress}

has also been accepted for indexing on PubMed Central. The manuscript management system is completely online and includes a very quick and fair peer-review system, which is all easy to use. Visit http://www.dovepress.com/testimonials.php to read real quotes from published authors. 